\title{
Math Design of the Airborne Evaporation Circulatory System
}

\author{
YinSai Guo ${ }^{1, a^{*}}$, Yi Zhang ${ }^{1, b}$, Meng Yi Zhang $^{1}$ and XiangFu Zeng ${ }^{1}$ \\ ${ }^{1}$ School of Mechanical Engineering, Xijing University, X'an710123, China; \\ a*guoysxj@163.com, brhangyjd@163.com
}

\begin{abstract}
Keywords: Math Design; Thermodynamic Calculation; Compressor; Condenser; Evaporator; Expansion Valve.
\end{abstract}

\begin{abstract}
The researches on a vapor cycle system start late in China. The vapor cycle cooling system is not a mature technolog. With the aid of advanced refrigeration technology at home and abroad, this paper focuses on research and development of the vapor cycle cooling system of the helicopter. Based on the design parameters of the vapor cycle cooling system, this paper carries out the match design, determines the operation condition and thermodynamic cycle pressure-enthalpy chart, conducts thermodynamic calculation, and obtains the main performance parameters and the required refrigerating capacity, which provides a basis for the match design in the actual system.
\end{abstract}

\section{Introduction}

The environment control system of serving military helicopter mostly adopts the model of the former Soviet Union in China. Its system is mainly the air circulation system [1, 2]. The high temperature and high pressure air from the engine through the turbine cooler work outside, so as to realize the refrigeration. As the attachment of system structure is relatively simple, and the volume and quality is small, it can adapt to the helicopter flying in different environment. As the modern electronic equipment increase on the helicopter, a quantity of heat which they produce is also increasing. The part of the region's climate is subtropical in China, and adopting soviet-made system cannot fully satisfy this kind of weather conditions. When summer comes, if the height of the flight is very low, its refrigerating capacity won't meet cooling demand of the modern helicopter. Therefore, the research and development of airborne evaporation circulatory system can solve this difficult problem [3].

\section{Working Parameters}

Working parameters of evaporation circulating cooling system: before the system thermodynamic calculation, the researcher determine the condensation temperature (tk), evaporation temperature ( $\mathrm{t} 0$ ), degree of super-cooling ( $\Delta$ TSC) and the degree of super-heat ( $\Delta$ TSC).

The condensation temperature tk. The cooling medium and structure of condenser decide the tk. Under normal circumstances, the condenser is the air-cooled condenser, and the temperature tk chose exceeds inlet air temperature of the condenser tw about $12{ }^{\circ} \mathrm{C} \sim 15{ }^{\circ} \mathrm{C}$.

As the air-cooled condenser is easy to get dust and other stuff and is limited by installation of volume, the volume of a condenser cannot very big. Its heat transfer coefficient is low. The tk is often improved by raising the temperature difference of heat transfer. Therefore, tk set is higher than the external environment temperature $17^{\circ} \mathrm{C}$, namely $\mathrm{tk}=\mathrm{tw}+17=50+17=67^{\circ} \mathrm{C}$. 
The evaporation temperature to. From the formula $\mathrm{Q}=\mathrm{KF} \Delta \mathrm{t}$, as the limitation of air-cooled condenser, $\mathrm{K}$ cannot have a big increase; F - heat exchange area, F is limited by the installation dimensions. The improvement of the refrigeration capacity must increase the heat transfer temperature difference $\Delta \mathrm{t}$. Once the return air temperature of the circulating cooling system was determined, if add heat transfer temperature difference $\Delta \mathrm{t}$, it will reduce the evaporation temperature $\mathrm{t} 0$, but it cannot fall too low. If the $\mathrm{t} 0$ is less than $0{ }^{\circ} \mathrm{C}$, part of the evaporator finned may be frost and this will reduce air output. In addition to consider people's comfortable, supply air temperature difference cannot be less than $8{ }^{\circ} \mathrm{C}$ to $10{ }^{\circ} \mathrm{C}$. Usually evaporation temperature is $\mathrm{t} 0=\mathrm{t} 2$ $\mathrm{x}(\mathrm{x}=8,9,10): \mathrm{t} 2$ - evaporation circulatory system supply air temperature $\left({ }^{\circ} \mathrm{C}\right)$. Therefore, eventually determine appropriate evaporation temperature $\mathrm{t} 0=0{ }^{\circ} \mathrm{C}$.

The degree of super-cooling $\Delta$ tSC and super-cooling temperature Tsc. Under the same pressure, tk is higher than the tSC $3{ }^{\circ} \mathrm{C} \sim 5{ }^{\circ} \mathrm{C}$; actual temperature: $\Delta \mathrm{tSC}=5{ }^{\circ} \mathrm{C} \sim 8{ }^{\circ} \mathrm{C}$.

The degree of supe rheat $(\Delta$ tsc). As make the compressor dry compression, and increase the effective heat transfer area of evaporator, its export degree of superheat usually is $5{ }^{\circ} \mathrm{C} \sim 7{ }^{\circ} \mathrm{C}$. For the helicopter evaporation circulatory system, the compressor suction temperature is $15{ }^{\circ} \mathrm{C}-18{ }^{\circ} \mathrm{C}$. When the evaporation temperature is $0{ }^{\circ} \mathrm{C}$, the effective superheat is $5{ }^{\circ} \mathrm{C} \sim 7{ }^{\circ} \mathrm{C}$; invalid superheating temperature is $10{ }^{\circ} \mathrm{C} \sim 11{ }^{\circ} \mathrm{C}$, the overall degree of superheat $\Delta$ tsc is $5{ }^{\circ} \mathrm{C}-18{ }^{\circ} \mathrm{C}$.

\section{Thermodynamic Calculation}

In the regulation design conditions, various performance parameters are obtained through thermodynamic calculation of evaporation circulating cooling system, to prepare for the next part design match. R134a is selected as refrigerants $[4,5]$. Thermal properties diagram of R134a is shown in Fig. 1.
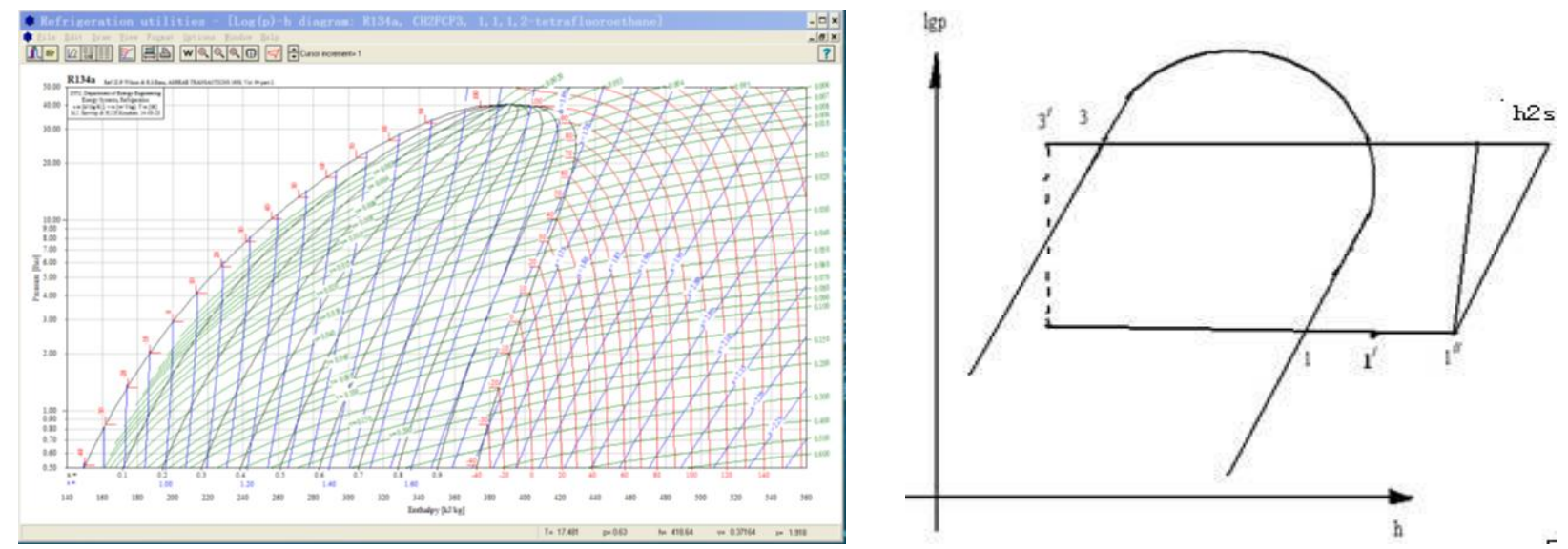

Fig. 1 R134a Thermodynamic Property

Fig. 2 Refrigeration Cycle Pressure Enthalpy Diagram

When the condensation temperature is $\mathrm{tk}=67^{\circ} \mathrm{C}$, the evaporating temperature $\mathrm{t} 0=0{ }^{\circ} \mathrm{C}$. From the Fig. 1, its saturation pressure: $\mathrm{Pk}=19.777 \times 105 \mathrm{~Pa}, \mathrm{P} 0=2.928 \times 105 \mathrm{~Pa}, \Delta \mathrm{tsc}=7^{\circ} \mathrm{C}, \Delta \mathrm{tsc}=15^{\circ} \mathrm{C}$.

According to the design and working condition, the refrigeration cycle pressure enthalpy graph (lg - $\mathrm{h}$ figure) is decided, which is shown in Fig. 2.

The key parameter values of the cycle evaporation cooling system of R134a thermodynamic properties figure are found out from Fig. 1.

$\mathrm{t}_{0}=0^{\circ} \mathrm{C}, \mathrm{P}_{0}=2.928 \times 10^{5} \mathrm{P}_{\mathrm{a}} ; \mathrm{t}_{\mathrm{k}}=67^{\circ} \mathrm{C}, \mathrm{P}_{\mathrm{k}}=19.777 \times 10^{5} \mathrm{P}_{\mathrm{a}}, \mathrm{t}_{1}{ }^{\prime}=7^{\circ} \mathrm{C}, \mathrm{t}_{1}{ }^{\prime \prime}=15^{\circ} \mathrm{C} ; \mathrm{t}_{3}{ }^{\prime}=60^{\circ} \mathrm{C}$. Each point of the enthalpy: $\mathrm{h}_{1}{ }^{\prime}=405 \mathrm{KJ} / \mathrm{kg}, \mathrm{v}_{1}{ }^{\prime}=0.07 \mathrm{~m}^{3} / \mathrm{kg} ; \mathrm{h}_{1}{ }^{\prime \prime}=412 \mathrm{KJ} / \mathrm{kg}, \mathrm{v}_{1}{ }^{\prime \prime}=0.073 \mathrm{~m}^{3} / \mathrm{kg} ; \mathrm{h}_{2}{ }^{\prime}=455 \mathrm{KJ} / \mathrm{kg}$, $\mathrm{h}_{3}{ }^{\prime}=278.4 \mathrm{KJ} / \mathrm{kg}, \mathrm{h}_{3}=299 \mathrm{KJ} / \mathrm{kg}$. 


\section{Math Design}

The Matching of Compressor. Under the design conditions, the refrigerating capacity of the compressor need:

$Q_{1}=\mathrm{q}_{e} \frac{Q_{0}}{q_{0}}=133.6 \times \frac{3}{126.6}=3.2 \mathrm{KW}$

$\mathrm{qe}=\mathrm{h} 1 / /-\mathrm{h} 3 /=412-278.4=133.6 \mathrm{KJ} / \mathrm{kg}$

In the formula: qe - Unit mass refrigerating capacity of compressor;

q0 - Unit mass refrigerating capacity of the airborne evaporation circulatory system;

Q0-Refrigerating capacity.

The Matching of Condenser. Condenser type matching is mainly based on its heat transfer area.

The unit heat load:

$$
\begin{aligned}
& \mathrm{h} 2 \mathrm{~s}=\mathrm{h} 1 / /+(\mathrm{h} 2 /-\mathrm{h} 1 / /) / \quad \eta_{i}=465.75 \mathrm{KJ} / \mathrm{kg} \\
& \mathrm{qk}=\mathrm{h} 2 \mathrm{~s}-\mathrm{h} 3 /=187.35 \mathrm{KJ} / \mathrm{kg} \\
& \text { Heat load: } \\
& \mathrm{QK}=\mathrm{qm} \bullet \mathrm{qk}=4.44 \mathrm{KW}
\end{aligned}
$$

Heat transfer area calculation formula:

$$
F=\frac{Q_{k}}{K \Delta t_{m}}
$$

In the formula: $\mathrm{F}$ - Heat transfer area; $\mathrm{K}$ - Heat transfer coefficient; $\Delta t_{m}$-Heat transfer temperature difference.

Heat transfer temperature difference:

$$
\Delta t_{m}=\frac{t_{a 2}-t_{a 1}}{\ln \frac{t_{k}-t_{a 1}}{t_{k}-t_{a 2}}}=\frac{8}{\ln \frac{67-43}{67-51}}=19.75
$$

In the formula: $t_{a 1}$-Inlet temperature, $43{ }^{\circ} \mathrm{C} ; t_{a 2}$-Outlet temperature, $51{ }^{\circ} \mathrm{C}$.

Heat transfer coefficient, $\mathrm{K}$ - refer to practical refrigeration engineering design manual, 1300 $\mathrm{w} /(\mathrm{m} 2, \mathrm{~K})$.

Heat transfer area:

$$
F=\frac{Q_{k}}{K \Delta t_{m}}=0.173 \mathrm{~m} 2
$$

The Matching of Evaporator. Evaporator type matching is mainly based on its heat transfer area.

The evaporator heat load: $\mathrm{Q} 0=3 \mathrm{KW}$

Heat transfer area calculation formula:

$$
F=\frac{Q_{0}}{K \Delta t_{m}}
$$

Heat transfer temperature difference: 


$$
\Delta t_{m}=\frac{t_{12}-t_{l 1}}{\ln \frac{t_{0}-t_{l 1}}{t_{0}-t_{l 2}}}=\frac{10}{\ln \frac{0-25}{0-15}}=19.57
$$

In the formula: $t_{l 2}$-Outlet temperature, $15{ }^{\circ} \mathrm{C}, t_{l 1}$ - Inlet temperature, $43{ }^{\circ} \mathrm{C}$.

Heat transfer coefficient, $\mathrm{K}$ - refer to practical refrigeration engineering design manual, 1100 $\mathrm{w} /(\mathrm{m} 2, \mathrm{~K})$.

$$
F=\frac{Q_{0}}{K \Delta t_{m}}=0.14
$$

The Matching of Throttling Expansion Mechanism. Balanced expansion valve is selected as the throttling expansion mechanism. System refrigerating capacity $3000 \mathrm{w}$, that is $3000 / 3300=0.909$ ton of refrigeration, so choose 0.9 tons of cold expansion valve.

\section{Summary}

Based on the design parameters of the vapor cycle cooling system, the match design is carried out. Determine the operation condition and thermodynamic cycle pressure-enthalpy chart, and carry on the thermodynamic calculation, and the main performance parameters, the required refrigerating capacity is achieved, which provides a basis for the match design in the actual system.

\section{Acknowledgements}

This work was supported by the Scientific Research Program Funded by Shaanxi Provincial Education Department (Program No. 2013JK1204) and the Natural Science Foundation of Shaanxi Province (Program No. 2013JM8040), Graduate Student Innovation Fund of Xijing University.

\section{References}

[1] M. Jonqueres. Air Cycle Environmental Control System With Vapor Cycle System[P].US005918472A, Jul.6, 1999.

[2] B. P. Rasmussen, A. G. Alleyne. Dynamic Modeling and Advanced Control of Air Conditioning and Refrigeration Systems[D]. 2006.

[3] C. S. Leonardo, J. L. H. Christian, T. N. Alexandre. A Model-driven multivariable controller for vapor compression refrigeration systems[J]. International Journal of Refrigeration, 2009, 33 (7): $12-14$.

[4] A. Beghi and L. Cecchinato. A Simulation Environment for Dry-Expansion Evaporators with Application to the Design of Auto tuning Control Algorithms for Electronic Expansion Valves[J]. International Journal of Refrigeration. 2009, 32(7): 22-26.

[5] Rodrganes H.C. Shape optimal design of elastic bodies using a mixed variational formulation[J]. Computer. Meth. Appl. Mech. Eng, 1987, 69. 